\title{
José Antonio Ramos y la Literatura Norteamericana
}

A primera impresión que recibe el norteamericano intelectualmente despierto, al conocer los círculos artísticos y literarios de la América hispánica, es la de un cosmopolitismo deslumbrante. Lejos de mostrarse provincial, el hombre culto de esa otra América, tan desconocida del americano del norte, bien puede ser un conocedor de Proust, un apasionado de los cuadros de Picasso, un perito en la dialéctica enredada de Lenin, o un ágil expositor de la música de Debussy. Consciente al fin de que su vecino hemisférico no es un indio salvaje ni un gaucho indomable, el intelectual yanqui se encuentra más a sus anchas, se pone expansivo, y tal vez menciona tímida y patrióticamente la literatura de los Estados Unidos. Le responde inevitablemente un coro de voces latinas entusiastas: $;$ Whitman, Poe; Poe, Whitman! Así casi al unísono, ya sea el lugar Costa Rica o la tentadora Argentina. De pronto este himno despierta en el pecho ingenuo del norteño un calor inusitado. i Al fin se ha encontrado - dice- el vínculo, tan ansiosamente buscado por el Departamento de Estado, que unirá culturalmente las Américas!

Pero, andando el tiempo (frenéticamente, como anda este caballero en las tertulias latinas), el norteamericano se da cuenta de que Poe, Whitman y muy pocos más son casi el principio y el fin de la literatura de los Estados Unidos para el mundo latino de América. Es verdad que algunos de los más entendidos hablan distraidamente de Pearl Buck, de Waldo Frank (gran favorito de los de habla española por su amor casi místico por la tradición hispánica), o de John Dos Passos. Y siempre hay alguno que otro vejete que recuerda las excelentes traducciones de Longfellow hechas hace un sin fin 
de años por algunos distinguidos colombianos y cubanos. Sin embargo, de una manera general podemos decir que el culto hispanoamericano, que por otra parte está tan versado en los secretos europeos de la cultura, apenas conoce la literatura o el pensamiento del Coloso del Norte, sino por convencionalismos ya un tanto gastados: la leyenda bohemia de Poe, la métrica un poco novelera de Whitman, y el run-run comercial y engañoso del "best-seller".

Claro está que hay excepciones importantes: hay izquierdistas que con un esfuerzo tal vez algo sectario se han profundizado en las obras de Hemingway, de Langston Hughes, de Upton Sinclair $y$ de otros que han retratado el caos estético y moral que ha creado el capitalismo desenfrenado en los Estados Unidos. Hay otros, más eclécticos, que han comentado en las páginas de esta revista las novelas magistrales de Thomas Wolf o de otros contemporáneos. O hay los que han leído con cariño los dramas de Eugene O'Neill. Recuerdo especialmente a León Mirlas, argentino, que ha analizado agudamente la obra de este dramaturgo. Algunos, como García Monge y la directiva de Sur, siempre han prestado atención generosa a lo que hacian nuestros literatos.

Por lo demás, es cierto que en los últimos años, sobre todo durante los años de la guerra cuando fallecía el poder magnético de las letras europeas, ha habido una verdadera inundación de traducciones al español de obras norteamericanas. Pero desgraciadamente lo traducido no ha sido siempre lo mejor y lo más escogido de la producción literaria de los Estados Unidos. Como dice muy bien el doctor John Englekirk, al presentar en esta revista su valiosa "Bibliografía de obras norteamericanas en traducción española" (Revista Iberoamericana, viII, 379; noviembre, 1944), "Se entenderá mejor el concepto erróneo y falso que se ha tenido de este país y de nuestra cultura; y se comprenderá que por algo las personas de gusto exigente se han quejado de que sólo les ha llegado lo mediocre de la literatura norteamericana, acusación que fácilmente se puede defender a base de los datos aquí proporcionados."

Pero vale repetirlo, sin temor de que nadie me contradiga sustancialmente: el hispanoamericano que lee libros apenas sabe que en los Estados Unidos hemos desarrollado una literatura rica, integral, muy americana y humana, digna de consideración y estudio. Sobre todo es una fuente clara y sincera en que se puede sonsacar una explicación verídica y documental de la formación de la nacionalidad 
norteamericana, un compendio dramático de nuestra grandeza, de nuestra idiosincrasia y de nuestras debilidades.

Para los de habla española que quieran acercarse a esa fuente existe afortunadamente una guía única y sumamente útil, Panorama de la literatura norteamericana, * por José Antonio Ramos. El autor fué hasta el día de su muerte en 1946 un enemigo declarado del imperialismo yanqui o de imperialismos de cualquiera procedencia. Abiertamente protestante, disidente, pero a la vez leal idólatra de la verdad en cualquiera manifestación, Ramos fué siempre aficionado de la literatura norteamericana. No lo fué, como algunos hermanos suyos, por motivos puramente estéticos, convencionales, o hasta interesados, sino porque veía en esa literatura una explicación emotiva de nuestro modo de ser. Comprendió claramente que los Estados Unidos podían producir no sólo geniales espíritus técnicos, como Tomás Edison y sus admirables colegas, sino también hombrès de hondo sentir humano, como Teodoro Dreiser, Emerson y tantos otros. Se dió cuenta de que al lado del egoísmo explotador del mundo de los negocios, ha habido en el Norte corrientes idealistas y cuerdamente humanitarias que han encontrado su expresión en la literatura.

El interés de José Antonio Ramos por la literatura de la república vecina de su patria, le coloca entre el grupo bastante numeroso de cubanos ilustres que, por sus largos destierros, llegaron a conocer y a estimar la vida literaria de los Estados Unidos. Casi se puede decir que Cuba fué durante gran parte del siglo XIx una maestra docta y paciente que daba lecciones sobre las letras norteamericanas para todo el mundo de habla española. Recuérdense los ensayos de Juan Clemente Zenea, que forman la primera historia de literatura norteamericana en español, o los artículos comprensivos de Martí sobre Emerson y Whitman y otros destacados de la época.

El propósito de Panorama de la literatura norteamericana es el de presentar un cuadro sinóptico desde los días coloniales hasta la época contemporánea. Como el libro es breve y conciso, es evidente que el autor nos ofrece un manual, una guía, más bien que un estudio detallado y completo. Sin embargo, no está reducido, ni mucho menos, a los huesos secos de listas de nombres y fechas, como lo están tantos manuales de literatura. En cada página encontramos interpretaciones, comentarios y agudos juicios personales del autor. Para

* México (Ed. "Botas"), 1935. 
manejar este libro de una manera inteligente, el lector debe recordar que Ramos no lo escribió como erudito frío y marmóreo, y no quiso perderse en una hojarasca de datos o en una engañosa objetividad.

El criterio literario del autor es por lo general materialista, liberal o izquierdista. Es decir, para él la literatura es resultado y a la vez reflejo de factores económicos y sociales y desde este punto de vista estudia las corrientes literarias de los Estados Unidos, siguiendo así las dignas huellas de Parrington y Charles Beard. Benjamín Franklin, por ejemplo, es fiel representante del capitalismo burgués protestante, y se hace hincapié en el ambiente formativo "pecuniolátrico" que determinó el carácter de los escritos de Mark Twain. No obstante, ningún sectarismo ofusca la visión crítica de Ramos. Por mucho que parezca un libro de sociología, su Panorama revela bien a las claras que es un artista sensible el que escribe, y sus juicios, si no siempre serenos y académicos, llevan el legítimo sello de sinceridad y de estimación por lo bello, sea la obra comentada de conservador político o de rebelde social.

Lo que presta valor especial a la guía de Ramos para el lector hispanoamericano es que el autor siempre tiene como fondo de su narración el problema de la América española. Para él la literatura y el desarrollo social de los Estados Unidos no son un mundo aparte cuyos rasgos característicos tienen un interés tan sólo teórico para la otra América y nada más. Como el leal caballero andante de justicia social que siempre fué durante su vida, Ramos busca en el modo de ser de la América del Norte contrastes y semejanzas con su propio mundo, ejemplos que valen imitarse o que deben evitarse en la América Latina. Ejemplos: nuestra literatura colonial le sugiere comparaciones con el fenómeno colonial en el imperio español, comparaciones nada favorables para España. E1 ambiente cultural norteño antes de Mark Twain y de Bret Hart le ofrece analogías que parecen exactas con el mundo literario actual de tantas partes de Hispanoamérica: literatura de imitación, de tanteos americanistas, ambiente que no encuentra todavía su apoyo en un gran público culto y lector. Ramos percibe semejanzas notables entre la literatura típica del sur de los Estados Unidos y el esfuerzo literario característico de muchas repúblicas iberoamericanas: literatura regional, conservadora, hasta feudal. $Y$ así por todas sus páginas es evidente su preocupación por la América Latina. 
Durante diez años Ramos fué representante consular de Cuba, radicado en Filadelfia. En vez de invertir sus ratos de ocio en la infructuosidad que tantas veces acompaña la vida oficial, los pasó frecuentando bibliotecas y sacando notas de sus lecturas de literatura norteamericana. Su Panorama es la sistematización de esos apuntes, pero desgraciadamente el autor tuvo que dejar su puesto consular por motivos políticos antes de terminar plenamente sus investigaciones literarias. Según lo que Ramos mismo me dijo una vez, el libro fué entregado a la imprenta algo precipitadamente cuando estuvo en México; tal vez esta ausencia de sus fuentes originales explica cierto carácter tentativo que es evidente en algunas de sus páginas.

En 1946, pocos meses antes de su muerte, José Antonio Ramos, como distinguido hombre de letras, fué invitado por el Departamento de Estado de los Estados Unidos a pasar algunos meses en este país como huésped del gobierno estadounidense. Durante su estancia aquí disfrutó de las facilidades de la biblioteca de la Universidad de Harvard y de la Biblioteca del Congreso para revisar su Panora$m a$, ampliando datos incompletos y añadiendo varias páginas en que estudia a escritores recientes. La muerte le llamó antes de que le fuera posible hacer los arreglos definitivos para una segunda edición de la obra. Pero el manuscrito, completo con las enmiendas y adiciones en la esmerada letra de nuestro amigo, queda en manos admiradoras y es de esperar que pronto salga a luz la segunda edición, que tanta falta hace.

JoHn T. ReID,

Universidad de California, Los Angeles. 
